\title{
Buddy microcatheter technique: Could it be the solution for complex coronary lesions?
}

\author{
Suleyman Sezai Yildiz, Serhat Sigirci, Kudret Keskin and Kadriye Kilickesmez \\ Department of Cardiology, Sisli Hamidiye Etfal Training and Research Hospital, Istanbul, Turkey
}

\begin{abstract}
The most common reason for a complex coronary lesion percutaneous coronary intervention failure is inability to cross the lesion with a guidewire, balloon or stent. Various techniques have been tried to solve the problem. We report on a 47-year-old man with subtotal occlusion of the proximal part of the left circumflex-obtus margine artery (LCXOM). He underwent coronary angiography and then percutaneous angioplasty. During the procedure, attempts to advance a wire beyond a target lesion failed due to LCX with a perpendicular angle and a sharp bend. With the use of the buddy microcatheter technique as inspired by buddy wire technique, successful balloon angioplasty and stent implantations were made at target lesion.
\end{abstract}

\section{Introduction}

Percutaneous coronary intervention (PCI) is a common used treatment tool for the management of patients with coronary artery disease. Severe tortious vessels, calcified and/or sharp-turned coronary lesions cause failure to cross the lesion, the balloon predilatation and the stent implantation during PCI [1,2]. The secret of successful intervention in these lesions is a powerful guiding catheter back up support. Deep intubation of extra back up (EBU) guiding catheter, buddy wires, anchoring balloon are the most common techniques used to reach the target lesions [3-5]. We here presented a successful balloon angioplasty and stent implantation using novel buddy microcatheter technique to reach target lesion and to cross left circumflex (LCX) that originated from the left main coronary artery with a perpendicular angle and had a sharp turn at its proximal part. To the best of our knowledge, this is the first report describing this novel technique for delivering balloon and stent to complex coronary lesions.

\section{Case report}

A 47-year-old male patient was admitted with diagnosis of non-ST elevation myocardial infarction (NSTEMI). Except for cardiac troponin $\mathrm{T}$, all routine biochemical tests were normal. The electrocardiogram showed sinus rhythm and negative $\mathrm{T}$ waves in the inferior leads. Coronary angiogram revealed left circumflex artery (LCX) with perpendicular angle and sharp turn, and 99\% lesion in proximal part of LCX -obtus margine artery (LCX-OM2) (Figure 1a and Video 1). Percutaneous coronary intervention was planned to the LCX-OM2 which was accepted as the culprit lesion. Extra backup 3.5 7Fr guiding catheter (Launcher, Medtronic) was intubated into the left main artery via the right femoral approach. And, Asahi soft 0.014-inch coronary guidewire (Abbott Vascular) was tried to advance to the LCX, however it could not be achieved. After that, hi-torque Whisper LS 0.014-inch guide wire (Abbott Vascular) was tried, which also failed since the wire was directed to the intermediate coronary artery (IMA) at each attempt due to perpendicular course and sharp turn of the LCX. Invader coronary balloon $2.5 \times 15 \mathrm{~mm}$ (Alvimedica, Turkey) was placed into the IMA over an Asahi soft wire as anchoring balloon technique (Figure 1b). Next, with the anchoring support of the

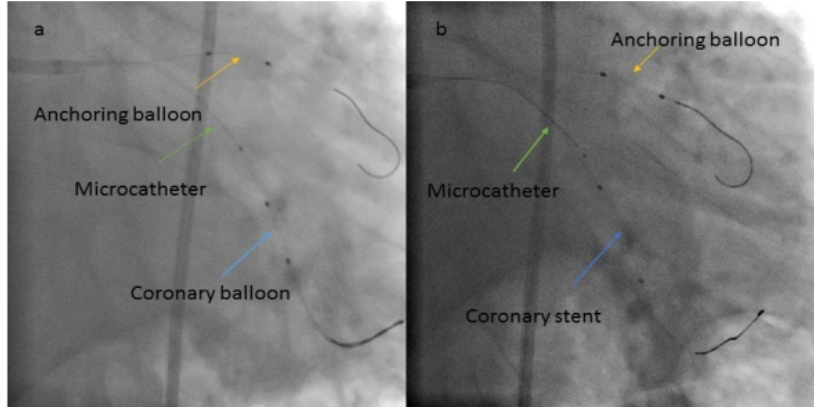

Figure 1. Images of coronary angiogram and intervention. (a) Leftanterior oblique projection with caudal angulation demonstratesperpendicular angle and sharp turn of LCX. (b) An anchoring balloon into the IMA. LCX: left circumflex artery; IMA: İntermediate artery

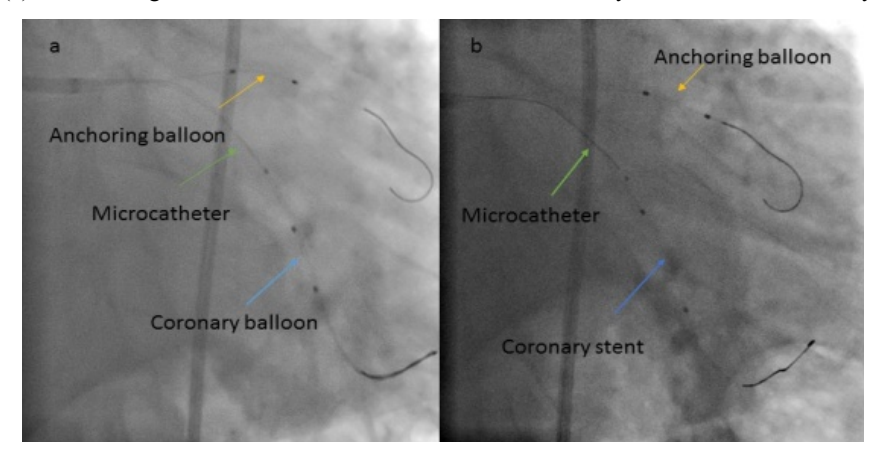

Figure 2. Images of coronary balloon and stent delivery. (a) Leftanterior oblique projection with caudal angulation illustrates balloon dilatation with the help of anchoring balloon and microcatheter. (b) Successful stent deployed via same technique at target lesion.

Correspondence to: Suleyman Sezai Yildiz, Deparment of Cardiology, Sisli Hamidiye Etfal Training and Research Hospital, Halaskargazi cad. Etfal Sk. 34371, İstanbul, Turkey, Tel: +90 21237350 00; Fax: +90 21222407 72; E-mail: sezai04@yahoo.com

Key words: buddy microcatheter technique, LCX -obtus margine artery, coronary stent

Received: June 27, 2017; Accepted: July 17, 2017; Published: July 20, 2017 
balloon and help of Finecross coronary microguide catheter (Terumo), Whisper LS wire was passed into the proximal LCX and advanced through OM2 artery. Second wire, Asahi soft wire was crossed to the lesion in the OM2 as buddy wire (Video 2). After, microcatheter was removed back from the guide catheter by trapping technique. At this time, both wires were expelled from the coronary artery. After that, the lesion was recrossed by Whisper LS wire via microcatheter. Asahi soft wire was advanced to the lesion over microcatheter as working wire. For an easy advancement of the balloon and stent to the target lesion, and guide catheter stabilization, microcatheter was parked proximal to the OM2 lesion, as inspired by buddy wire technique (buddy microcatheter). Invader coronary balloon $2.0 \times 12 \mathrm{~mm}$ was easily advanced to the lesion by buddy microcatheter and dilated (Figure $2 \mathrm{a}$ and Video 3). Afterwards, $3.0 \times 18 \mathrm{~mm}$ Xience-Pro (Abbott Vascular) stent was advanced to the lesion as assisted by buddy microcatheter and dilated. Next, microcatheter and the second wire were removed back (Figure $2 \mathrm{~b}$ and Video 4). A good result was provided, with TIMI 3 flow and no residual dissection (Videos 5 and 6). Total duration of the procedure was 50 minutes and contrast material administered was $230 \mathrm{ml}$. He was discharged after $48 \mathrm{~h}$ with aspirin, ticagrelor, ramipril, metoprolol and atorvastatin.

\section{Discussion}

Calcified, tortuous, and sharp-turned coronary lesions are challenged to perform a successful balloon angioplasty or coronary stent implantation by invasive cardiologists. The one or more buddy wire technique often uses as a track and helps advance of the balloon or the stent towards the target lesion [5,6]. Likewise, the use of microcatheter

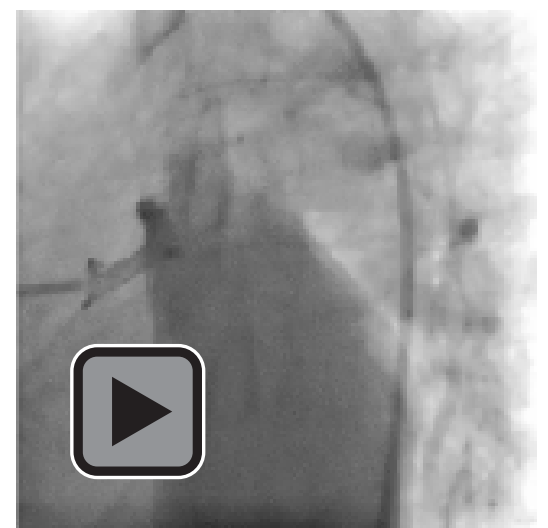

Video 1. Baseline coronary angiography demonstratessubtotally occlusion of LCXOM2.

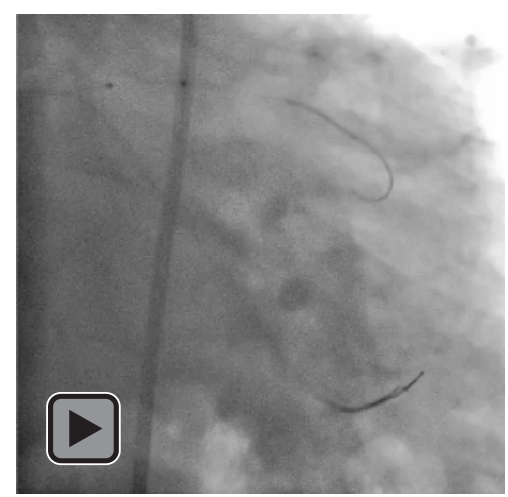

Video 2. Coronary angiography demonstrates advancing wire with the help of anchoring the balloon and microcathater.

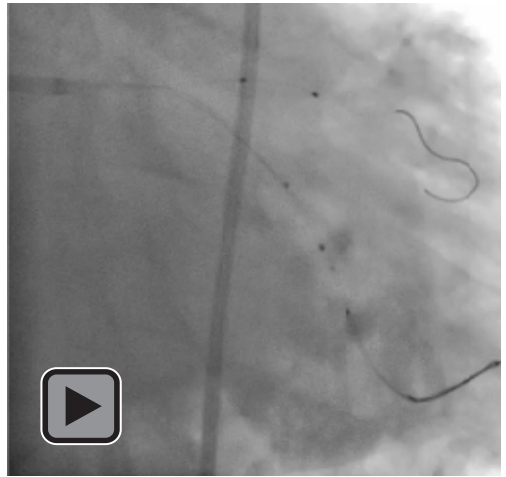

Video 3. The balloon is easily advancing to the lesion with the help of buddy microcatheter

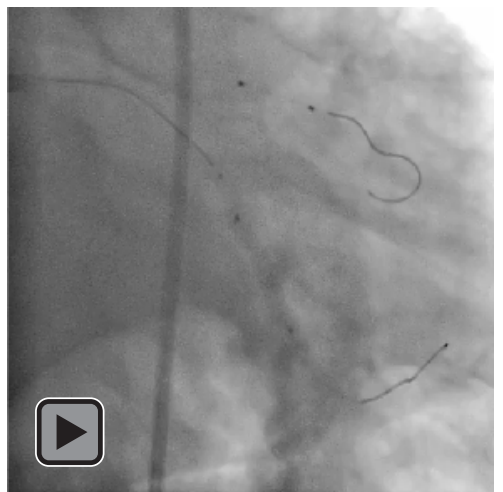

Video 4. Successfully stent implantation with support of buddy microcatheter.
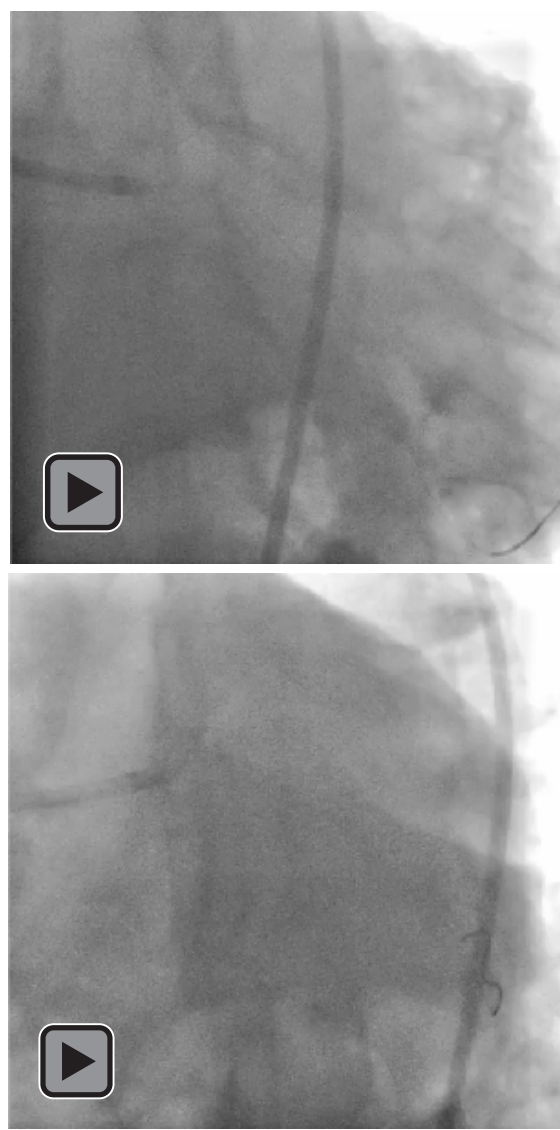

Video 5, 6: Left and right anterior oblique projection with caudal angulation demonstrates good result with TIMI 3 flow and no residual dissectionat LCXOM2. 
may significantly facilitate the success and efficiency of chronic total occlusion PCI and intracranial endovascular stroke and aneurysms treatment [7-9]. In our report, firstly the buddy wire technique was planned. But, it was failed. Also, the buddy balloon technique could not be used since the balloon could not be advanced despite utilization of buddy wire technique at target lesion. Two wires were advanced with the help of microcatheter. Finally, coronary microcatheter was parked proximal to the lesion as it easily crossed tortuous and sharpturned lesion. Therefore, both coronary balloon and coronary stent could be conveniently and safely conveyed to the target lesion. The buddy microcatheter technique as inspired by buddy wire technique can be helpful in several situations during PCI. Especially in lesions with marked tortuosities and sharp bend where the buddy wire and the buddy balloon techniques fail, it can aid to pass of target lesion and to stabilize the guiding catheter. We presented here a successful coronary stent implantation in tortuous and sharp-turned lesions where even coronary balloon could not be advanced to the target lesion, as inspired by buddy wire technique and assisted by the microcatheter, which was found at every catheterization laboratory.

\section{Conclusion}

The buddy microcatheter technique appears to be a helpful, reliable and promising approach for treating complex coronary lesions after failed stent deployment.

\section{References}

1. Nikolsky E, Gruberg L, Pechersky S, Kapeliovich M, Grenadier E, et al. (2003) Stent deployment failure: reasons, implications, and short- and long- term outcomes. Catheter Cardiovasc Interv 59: 324-328. [Crossref]

2. Burzotta F, Trani C, Mazzari MA, Mongiardo R, Rebuzzi AG, et al. (2005) Use of a second, "buddy" wire during percutaneous coronary interventions: a simple solution for some challenging situations. J Invasive Cardiol 17: 171-174. [Crossref]

3. KaluskiE, Tsai S, Milo-Cotter O (2007) Buried Wire Technique: Enhancing Support Method for Complex Percutaneous Interventions and Stenting. J Invasive Cardiol 19: 95-96. [Crossref]

4. Fujita S, Tamai H, Kyo E, Kosuga K, Hata T, et al. (2003) New technique for superior guiding catheter support during advancement of a balloon in coronary angioplasty: the anchor technique. Catheter Cardiovasc Interv 59: 482-488. [Crossref]

5. Goldberg A, Klein R, Marmor A (2007) Buddy wire, buddy balloon or better together! J Invasive Cardiol 19: 363-365. [Crossref]

6. Dana A, Barbeau GR (2006) The use of multiple "buddies" during transradial angioplasty in a complex calcified coronary tree. Catheter Cardiovasc Interv 67: 396399. [Crossref]

7. Karatasakis A, Tarar MN, Karmpaliotis D, Alaswad K, Yeh RW, et al. (2017) Guidewire and microcatheter utilization patterns during antegrade wire escalation in chronic total occlusion percutaneous coronary intervention: Insights from a contemporary multicenter registry. Catheter Cardiovasc Interv 89: E90-E98. [Crossref]

8. Kitahara T, Hatano T, Hayase M, Hattori E, Miyakoshi A, et al. (2017) Jailed doublemicrocatheter technique following horizontal stenting for coil embolization of intracranial wide-necked bifurcation aneurysms: A technical report of two cases. Interv Neuroradiol 23: 117-122. [Crossref]

9. Park H (2015) A suction thrombectomy technique: a rapid and effective method for intra-arterial thrombolysis. J Cerebrovasc Endovasc Neurosurg 17: 13-19. [Crossref]

Copyright: (C2017 Yildiz SS. This is an open-access article distributed under the terms of the Creative Commons Attribution License, which permits unrestricted use, distribution, and reproduction in any medium, provided the original author and source are credited. 